\title{
Comparison of performance of the Assessment of Spondyloarthritis International Society, the European Spondyloarthropathy Study Group and the modified New York criteria in a cohort of Chinese patients with spondyloarthritis
}

\author{
Ho Yin Chung $\cdot$ Chak Sing Lau $\cdot$ Ka Pik Wu • \\ Woon Sing Wong $\cdot$ Mo Yin MOK
}

Received: 22 June 2010 /Revised: 7 December 2010 /Accepted: 13 January 2011 /Published online: 19 February 2011

(C) The Author(s) 2011. This article is published with open access at Springerlink.com

\begin{abstract}
Early diagnosis of spondyloarthritis ( $\mathrm{SpA}$ ) is essential as anti-tumor necrosis factor therapy can achieve significant symptomatic relief and control of disease activity. This study aims to compare the clinical characteristics, disease activity, and functional status of a Chinese cohort of SpA patients who were re-classified into ankylosing spondylitis (AS) patients fulfilling the modified New York (MNY) criteria, those with undifferentiated SpA (USpA) fulfilling the European Spondyloarthropathy Study Group (ESSG) classification criteria only (USpA/ESSG) and those who fulfill Assessment of SpondyloArthritis International Society (ASAS) only (USpA/ASAS). Disease activity was evaluated by Bath Ankylosing Spondylitis Disease Activity Index (BASDAI), severity of morning stiffness, patient global assessment, and C-reactive protein. Functional status was evaluated by Bath Ankylosing Spondylitis Functional Index (BASFI), modified Schober index, and dimension of chest expansion. One hundred and twenty-eight patients with disease duration of $16.3 \pm 10.4$ years were recruited. Patients in USpA/ESSG and USpA/ASAS were significantly younger $(p=0.01)$, had shorter disease duration $(p<0.01)$, and lower BASFI $(p=0.03)$ than established AS patients. All three groups have active disease with comparable BASDAI $>3$.
\end{abstract}

H. Y. Chung $\cdot$ C. S. Lau $\cdot$ W. S. Wong $\cdot$ M. Y. MOK $(\bowtie)$

Department of Medicine,

Queen Mary Hospital, The University of Hong Kong,

Hong Kong, SAR China

e-mail: temy@hkucc.hku.hk

K. P. Wu

Department of Radiology, Queen Mary Hospital,

The University of Hong Kong,

Hong Kong, SAR China
BASFI correlated inversely with dimension of chest expansion and negatively modified Schober index in AS patients $(p<0.01)$ and modestly with BASDAI $(r=0.25, p<0.01)$. BASFI correlated moderately with BASDAI in USpA/ESSG $(r=0.61, p<0.01)$ but not with chest expansion or modified Schober index. Compared with established AS patients recognized by MNY criteria, patients fulfilling USpA defined by ESSG or ASAS criteria had earlier disease, as active disease and less irreversible functional deficit.

Keywords Classification criteria - Disease activity . Functional status $\cdot$ Spondyloarthropathy

\section{Introduction}

Spondyloarthritis $(\mathrm{SpA})$ describes a spectrum of chronic inflammatory spinal diseases characterized by progressive spinal deformity and impaired mobility. The spectrum is represented by undifferentiated SpA (USpA) on one end, where there are minimal symptoms and changes on plain radiography and by ankylosing spondylitis (AS) with established radiological sacroiliitis on the other end. Chronic inflammatory low back pain and radiographic changes involving the sacroiliac (SI) joints are key diagnostic features for AS according to the modified New York (MNY) criteria established in 1984 [1]. Although the MNY criteria have been widely used in both clinical and research settings, the criteria are not sensitive enough to identify patients with early disease as radiological changes on plain X-ray are only apparent a number of years after onset of spinal symptoms and often represents structural 
damage in advanced disease [2]. Around $50 \%$ of $\mathrm{SpA}$ patients are characterized by extra-spinal features [3] that form the basis for the European Spondyloarthropathy Study Group (ESSG) classification criteria established in 1990 [4], which have higher sensitivity of diagnosis of USpA. The ESSG criteria do not require presence of radiological features, the sensitivity can be affected by the prevalence of $\mathrm{SpA}$ in the locality and the number of associated features and are thus deficient in the diagnosis of axial SpA [5, 6]. HLA-B27 serotyping and magnetic resonance imaging (MRI) scan of the SI joints are nowadays recommended to assist early diagnosis of axial SpA in patients with inflammatory back pain who lack radiographic sacoiliitis [7].

There is a compelling need for early diagnosis of patients with $\mathrm{SpA}$ as biologic therapy against tumor necrosis factor-alpha (TNF- $\alpha$ ) has been shown to achieve significant improvement in symptoms and control of disease activity in these patients $[8,9]$. The Assessment of SpondyloArthritis International Society (ASAS) has validated a newly developed classification criteria in June 2009 incorporating the use of Human Leucocyte Antigen-B27 (HLA-B27) serotyping and MRI features of early sacroiliitis to identify early axial SpA patients [10]. The ASAS criteria have not been validated in patients of Chinese ethnicity. Our study aimed to examine a local cohort of SpA patients, including those with definite and possible $\mathrm{SpA}$, previously diagnosed by rheumatologists before the establishment of ASAS criteria. These patients were reclassified according to the MNY, ESSG, and ASAS classification criteria into three groups, namely: (1) patients fulfilling the MNY criteria, i.e., AS patients; (2) USpA patients defined according to the ESSG criteria only (USpA/ESSG); and (3) USpA patients fulfilling the ASAS classification criteria only (USpA/ASAS). The clinical characteristics of these three groups of patients in terms of their demographic features, disease activity, and functional status were compared.

\section{Patients and methods}

This study adopted a prospective cross-sectional design. Clinical, laboratory, and plain radiological assessments on the recruited subjects were performed on the same day at the clinic visit. Further investigations, including HLA-B27 serotyping and MRI sacroiliac joints, were arranged within 4 weeks for those subjects who did not show definite sacroiliitis on plain X-ray. The study was approved by the ethics committee of the Institutional Review Board of the University of Hong Kong/Hospital Authority Hong Kong West Cluster and conducted in accordance with the Declaration of Helsinki. Consecutive patients of Southern
Chinese ethnicity were recruited from the universityaffiliated rheumatology clinic with informed consent. These patients had been diagnosed to have definite or possible $\mathrm{SpA}$ according to rheumatologist opinion before the introduction of the ASAS criteria in 2009. Medical history and physical examination were conducted by the same rheumatologist (HYC) at the clinic visit. Patients who were currently or previously treated with biological agents were excluded. Demographic data including age, sex, disease duration, onset of symptoms, symptomatology, including the presence of inflammatory back pain, enthesitis, uveitis, aortic regurgitation, dactylitis, psoriasis, inflammatory bowel disease, urethritis, cervicitis, or acute diarrhea within the month preceding onset of arthritis, family history of $\mathrm{SpA}$, current and previous treatment including disease modifying anti-rheumatic drugs (DMARDs), and nonsteroidal anti-inflammatory drugs (NSAIDs) were retrieved from medical records and verified with patients at the clinic visit. Inflammatory back pain was defined by the presence of at least two of the following features: morning stiffness of $>30 \mathrm{~min}$, improvement with exercise but not with rest, awakening because of back pain during the second half of night, and alternating buttock pain [11]. Patients who had a history of acute-onset diarrhea within the month before arthritis onset and psoriasis, inflammatory bowel disease, urethritis, or cervicitis, and those currently or previously on biologic agents were excluded from the study.

Disease activity and functional ability in these patients were examined using the Chinese version of Bath Ankylosing Spondylitis Disease Activity Index (BASDAI) [1214] and the Bath Ankylosing Spondylitis Functional Index (BASFI) [15]. Severity of morning stiffness was determined by calculating the average score of questions 5 and 6 of BASDAI. Patient Global Assessment (PGA) was scored on a ten-point visual analogue scale (VAS). The BASDAI, BASDFI, and PGA score ranged from 0 to 10 . Physical examination was performed to determine spinal mobility including lumbar flexion [modified Schober index (MSI)] and chest expansion. Enthesitis was defined by tenderness on palpation over the insertions of the Achilles tendon or the plantar fascia. Peripheral arthritis was defined by warmth, swelling, or tenderness of the extra-spinal joints. Blood investigations including complete blood picture, liver and renal function tests, and $\mathrm{C}$-reactive protein (CRP) were measured. All subjects had radiographs of the SI joints, and the stages of sacroiliitis were graded according to MNY criteria. Chest $\mathrm{x}$-ray was taken to examine for presence of upper lobe pulmonary fibrosis. Echocardiogram was performed to examine for valvular heart lesion if cardiac murmur was detected on auscultation. Radiographs of the symptomatic peripheral joints were taken to detect joint erosion. Contrast MRI scan of the SI joints and HLA B27 typing were arranged for 
subjects who did not show radiographic changes of grade 2 or above on plain x-ray of the SI joints. All radiographs and MRI images were interpreted by the same radiologist (KPW).

These patients were then evaluated for their fulfillment of one or more of the three classification criteria: the MNY, ESSG, and ASAS classification criteria. The three groups of patients were then selected for comparison on their demographic and clinical features, disease activity, and functional status. Patients were reclassified into AS group if they fulfilled the MNY criteria, the "USpA defined by ESSG criteria" (USpA/ESSG) group if they fulfilled the ESSG criteria but not the MNY criteria and the "USpA defined by ASAS criteria only" (USpA/ASAS) group if they fulfilled the ASAS criteria but not the MNY or ESSG classification criteria.

Statistical analysis

Statistical analysis was performed by SPSS 16.0 (Chicago, USA). Continuous data was expressed as mean \pm standard deviation (SD) and categorical variables as counts and percentages. One-way ANOVA was used to compare parametric variables between groups. Mann-Whitney $U$ test was used for comparison of non-parametric data. Spearman's rank correlation was performed to determine correlation between different non-normally distributed variables. $P$ value of $<0.05$ was considered statistically significant in this study.

\section{Results}

One hundred and twenty eight consecutive Chinese patients with prior diagnosis of $\mathrm{SpA}$ were recruited. These included 92 male and 36 female patients. The mean \pm SD age of these patients were $43.8 \pm 13.7$ years with disease duration of $16.3 \pm 10.4$ years. One hundred and seventeen patients (91.4\%) had inflammatory back pain at disease onset or during the disease course. Ninety-two patients (71.9\%) fulfilled the MNY criteria, whereas 107 (83.6\%) fulfilled the ESSG criteria and 126 (98.4\%) fulfilled the ASAS classification criteria for axial SpA. Eighteen patients (14.1\%) met the ESSG but not the MNY criteria and were reclassified into the USpA/ESSG group. Another 18 patients (14.1\%) fulfilled the ASAS but not ESSG criteria for axial SpA and were reclassified into the USpA/ASAS group. Among these patients, $15(83.3 \%)$ had MRI features suggestive of early sacroiliitis, whereas HLA-B27 positivity was found in the remaining patients. Figure 1 shows reclassification of patients in our cohort into these three groups for subsequent comparison.

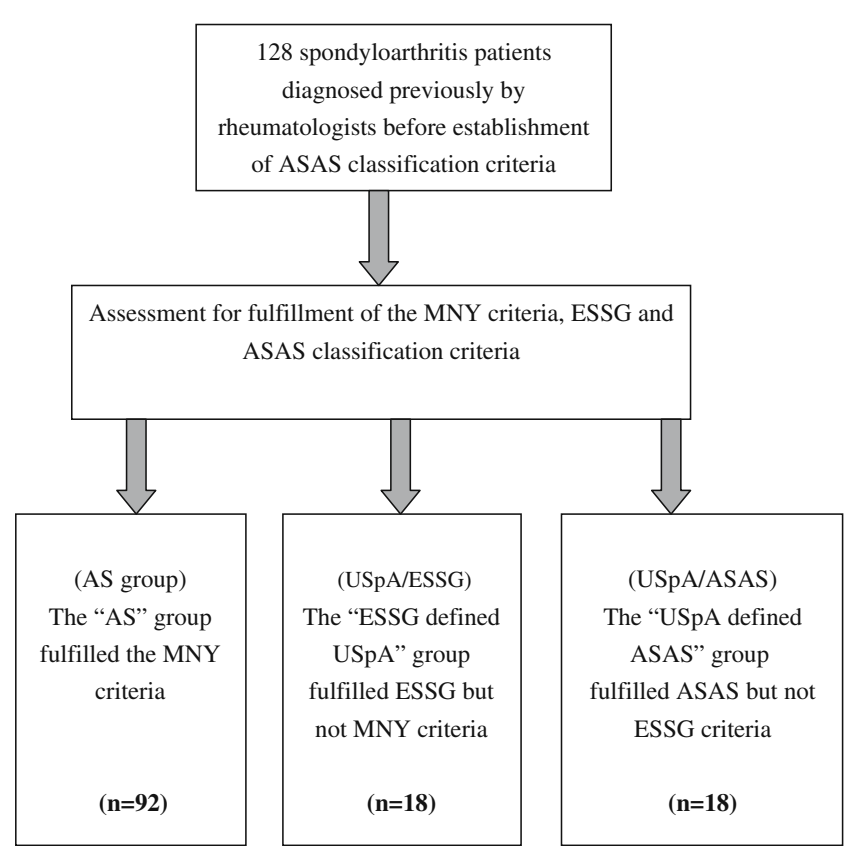

Fig. 1 Reclassification of spondyloarthritis patients according to the MNY criteria, ESSG and ASAS classification criteria

Demographic and clinical features

Table 1 shows the demographic and clinical features of patients reclassified into the AS, USpA/ESSG, and USpA/ASAS groups. AS patients were significantly older $(p=0.01$ by ANOVA) and had longer disease duration $(p<0.01)$ compared to patients in the other groups. The USpA/ASAS group tended to be younger $(37.4 \pm 6.4$ vs $38.3 \pm 5.2$ years; $p=0.83$ ) and had shorter disease duration $(9.2 \pm 2.3$ vs $11.6 \pm 3.8$ years, $p=0.25$ ) compared to the USpA/ESSG group, but the difference was not statistically significant. The prevalence of extra-spinal features including uveitis [16], upper lobe fibrosis [17-19], aortic regurgitation [20, 21], dactylitis, peripheral arthritis, and peripheral joint erosion were similar among the three groups and were comparable to those reported in Caucasian populations in the literature. Enthesitis (27.8\%) was a more frequent complaint in the USpA/ESSG group [22] compared to AS patients (7.6\%) and the USpA/ASAS group $(5.6 \%)(p=0.01)$. The use of medications, including NSAIDs and sulphasalazine, was not different between these groups.

Disease activity and functional status

Parameters of disease activity and functional status of the three groups are summarized in Table 2. BASDAI in AS, USpA/ESSG, and USpA/ASAS groups were $4.1 \pm 0.4,4.1 \pm$ 1.1 , and $3.5 \pm 0.9$ respectively. BASDAI $(p=0.42)$, severity of morning stiffness $(p=0.36)$, and CRP levels $(p=0.23)$ 
Table 1 The demographic and clinical manifestations of patients in the three reclassified SpA groups

\begin{tabular}{|c|c|c|c|c|c|}
\hline & AS group & USpA/ESSG group & USpA/ASAS group & $P$ value & Caucasian series $(30-36)$ \\
\hline Age (years) & $45.7 \pm 2.9$ & $38.3 \pm 5.2$ & $37.4 \pm 6.4$ & 0.01 & \\
\hline Male gender & $67(72.8 \%)$ & $10(55.6 \%)$ & $15(83.3 \%)$ & 0.17 & \\
\hline Disease duration (years) & $18.7 \pm 2.2$ & $11.6 \pm 3.8$ & $9.2 \pm 2.3$ & $<0.01$ & \\
\hline \multicolumn{6}{|l|}{ Clinical features } \\
\hline Uveitis & $45(48.9 \%)$ & $5(27.8 \%)$ & $7(38.9 \%)$ & 0.22 & $25-40 \%[16]$ \\
\hline Upper lobe fibrosis & $18(19.6 \%)$ & $3(16.7 \%)$ & $0(0.0 \%)$ & 0.12 & $1.3-30 \%$ [17-19] \\
\hline Aortic regurgitation & $3(3.3 \%)$ & $1(5.6 \%)$ & $0(0.0 \%)$ & 0.63 & $2-12 \%[20,21]$ \\
\hline Dactylitis & $12(13.0 \%)$ & $1(5.6 \%)$ & $1(5.6 \%)$ & 0.48 & N/A \\
\hline Enthesitis & $7(7.6 \%)$ & $5(27.8 \%)$ & $1(5.6 \%)$ & 0.01 & $22-27 \%[22]$ \\
\hline Peripheral arthritis & $41(44.6 \%)$ & $9(50 \%)$ & $7(38.9 \%)$ & 0.80 & $\mathrm{~N} / \mathrm{A}$ \\
\hline Joints erosion & $4(4.3 \%)$ & $0(0.0 \%)$ & $0(0.0 \%)$ & 0.45 & N/A \\
\hline \multicolumn{6}{|l|}{ Medications } \\
\hline NSAID & $77(83.7 \%)$ & $15(83.3 \%)$ & $16(88.9 \%)$ & 0.19 & \\
\hline Sulphalazine & $49(53.3 \%)$ & $11(61.1 \%)$ & $8(44.4 \%)$ & 0.98 & \\
\hline
\end{tabular}

$N / A$ not available

were comparable between these groups. The highest patient global assessment score were recorded among AS patients $(4.7 \pm 0.4)$ compared to the USpA/ESSG $(4.1 \pm 0.8)$ and USpA/ ASAS (3.6 \pm 0.9$)$ groups $(p=0.03)$. AS patients also had the highest BASFI $(p=0.03)$, lowest dimension of chest expansion $(p=0.01)$, and lowest modified Schober index $(p<0.01)$ among patients in these groups. There was no difference in BASFI $(p=0.60)$, chest expansion $(p=1.00)$, and modified Schober index $(p=1.00)$ between the USpA/ESSG and USpA/ ASAS patients.

Correlations between functional status reflected by BASFI, disease activity by BASDAI, and disease damage by chest expansion and the modified Schober index were determined in the three SpA groups (Table 3). Among AS patients, BASFI was found to correlate weakly with BASDAI $(r=0.25, p<0.01)$, and negatively with dimension of chest expansion $(r=-0.28 ; p<0.01)$ and the modified Schober index $(r=-0.38 ; p<.01)$. In the USpA/ESSG group, BASFI correlated moderately with BASDAI $(r=0.61, p<0.01)$ alone. BASFI in the USpA/ASAS group showed no correlation with BASDAI, chest expansion, and the modified
Schober index. Figure 2 shows the contribution of BASDAI expressed as a function of BASDAI/BASFI complex representing reversible and "relative" irreversible elements in the three SpA groups. Disease activity reflected by BASDAI accounted for $56.2 \%, 68.3 \%$, and $74.5 \%$ in AS patients, the USpA/ESSG, and USpA/ASAS groups, respectively.

\section{Discussion}

Our study demonstrated distinct clinical features of USpA patients classified by the ESSG or ASAS classification criteria compared to AS patients defined by the MNY criteria. The ASAS criteria demonstrated highest sensitivity (98.4\%) compared to the MNY (71.9\%) and the ESSG (83.6\%) criteria in our SpA cohort. A lower sensitivity for MNY criteria $(39.6 \%)$ but similar sensitivity by ESSG criteria $(87 \%)$ was reported in other cohorts of different ethnicities [23-26]. Around 5\% of patients presented with chronic inflammatory back pain at the primary care have been found to have underlying SpA [27]. Inflammatory
Table 2 Disease activity and functional status of patients in the three reclassified $\mathrm{SpA}$ groups

\begin{tabular}{lcccr}
\hline Disease activity & AS group & USpA /ESSG group & USpA/ASAS group & $P$ value \\
\hline BASDAI & $4.1 \pm 0.4$ & $4.1 \pm 1.1$ & $3.5 \pm 0.9$ & 0.42 \\
Severity of morning stiffness & $3.6 \pm 0.5$ & $3.1 \pm 1.2$ & $2.8 \pm 1.0$ & 0.36 \\
Patient global assessment & $4.7 \pm 0.4$ & $4.1 \pm 0.8$ & $3.6 \pm 0.9$ & 0.03 \\
CRP & $1.4 \pm 0.5$ & $0.5 \pm 0.5$ & $0.9 \pm 0.8$ & 0.23 \\
Functional status & & & & \\
BASFI & $3.2 \pm 0.6$ & $1.9 \pm 1.0$ & $1.2 \pm 0.7$ & 0.03 \\
Chest expansion $(\mathrm{cm})$ & $3.5 \pm 0.3$ & $4.6 \pm 0.6$ & $4.8 \pm 0.8$ & 0.01 \\
Modified Schober test $(\mathrm{cm})$ & $1.9 \pm 0.3$ & $3.7 \pm 0.7$ & $3.6 \pm 0.6$ & $<0.01$ \\
\hline
\end{tabular}


Table 3 Correlations between BASFI and BASDAI and spinal mobility in the three reclassified SpA groups

\begin{tabular}{lccc}
\hline Correlation coefficient with BASFI & AS group & USpA/ESSG group & USpA/ASAS group \\
\hline BASDAI & 0.25 & 0.61 & 0.48 \\
$P$ value & $<0.01$ & $<0.01$ & 0.73 \\
Modified Schober index & -0.38 & -1.27 & -0.08 \\
$P$ value & $<0.01$ & 0.22 & 0.82 \\
Chest expansion & -0.28 & -1.62 & -0.17 \\
$P$ value & $<0.01$ & 0.13 & 0.63 \\
\hline
\end{tabular}

back pain was reported by $93.7 \%$ of our patients, which is a key feature to most diagnostic criteria including the MNY and ASAS criteria. The presence of chronic inflammatory back pain has been shown to increase the positive likelihood ratio by 12-fold in the screening for SpA [11].

The ASAS and ESSG classification criteria have been developed aiming to encompass patients with USpA. Indeed, both sets of classification criteria were found to characterize $\mathrm{SpA}$ patients at an earlier stage who were younger and had shorter disease duration compared to the MNY criteria in our cohort. The ESSG involves extraspinal features as inclusion criteria, whereas the ASAS criteria involves MRI scan of the SI joints and HLA-B27 serotyping early in the diagnostic algorithm. MRI scan has been proven clinically useful in the management of SpA patients as it can detect early inflammatory changes in the SI joints to facilitate early diagnosis [28] and can reflect extent of spinal inflammation that has been shown to be a predictive factor of clinical response to anti-TNF therapy [29]. HLA-B27 serotyping, in addition to inflammatory back pain in the primary care setting, has been found to be

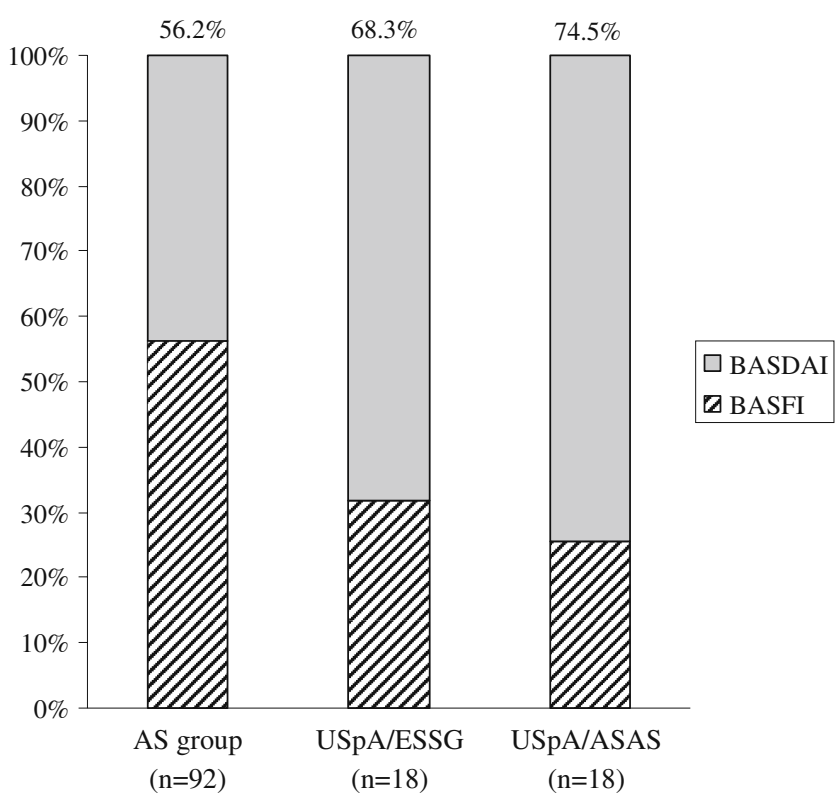

Fig. 2 The proportion of BASDAI in the BASDAI/BASFI complex representing reversible and "relative" irreversible elements in the three reclassified $\mathrm{SpA}$ groups the best measure to predict future development into AS [30]. Serum level of CRP was not different between these patients and had not been regarded as a satisfactory marker in the assessment of disease activity [31]. BASDAI of patients in these groups were above three, suggestive of active disease and was not different in level between USpA subjects and established AS patients. Thus, many of these patients who had early or late disease were indicated for anti-TNF therapy according to the ASAS recommendation $[32,33]$.

USpA patients recognized by the ASAS criteria were found to have the lowest BASFI revealing better functional status than the other groups. Recent studies showed that spinal mobility impairment is contributed by both spinal inflammation, as a reversible element, and irreversible spinal damage [34]. The better dimension of chest expansion and modified Schober index demonstrated by USpA patients recognized by ESSG and ASAS criteria may, thus, suggest that these patients had less irreversible damage. BASFI was found to correlate weakly with BASDAI and negatively with chest expansion and the modified Schober index in AS patients, suggesting both reversible and irreversible components contributing to worse functional status in established SpA. On the other hand, BASDAI was the only feature that correlated with BASFI in USpA patients recognized by ESSG criteria suggesting predominant contribution of functional status from reversible component that may be amendable to treatment and disease control. Thus, both ASAS and ESSG criteria appeared to identify USpA early before clinically significant chronic damage was apparent. Although we were not able to show significant difference in clinical characteristics between USpA defined by ESSG and ASAS criteria because of our small sample size, the ASAS criteria is expected to be more sensitive for diagnosing USpA including those patients who did not fulfill the ESSG criteria by incorporating MRI of the SI joints and HLA-B27 serotyping.

Around 59-68\% USpA patients have been reported to evolve progressively into established AS over 10 years [35, 36]. Although it remains controversial whether anti-TNF therapy in $\mathrm{SpA}$ will lead to retardation of disease progression [37-39], recognition of USpA early in the 
clinical course is associated with treatment implications as TNF blockers can offer significant symptomatic control, amelioration of disease activity, and improved quality of life [40-43]. Indeed, USpA patients who fulfill ESSG or ASAS criteria in our cohort demonstrated a number of clinical features that have been recognized to be predictors of better response to TNF blockers including shorter disease duration, lower BASFI, younger age, as well as raised ESR or CRP [44]. Thus, early treatment for better symptomatic relief and disease control is warranted in these patients with early disease.

This study is limited by the predominance of patients with established AS in our cohort. The small sample size of patients with USpA and early disease limited the statistical power to examine for any discriminative clinical characteristics between the ESSG and ASAS groups. We demonstrated highest sensitivity of diagnosis of SpA patients by the ASAS criteria among existing classification criteria. We showed that USpA patients had early disease with more reversible element to contribute to their functional status. With the availability of more efficacious treatment, early diagnosis can allow earlier symptom control, alleviation of disease activity, and hopefully, prevention of irreversible damage in patients with $\mathrm{SpA}$.

\section{Disclosures None.}

Open Access This article is distributed under the terms of the Creative Commons Attribution Noncommercial License which permits any noncommercial use, distribution, and reproduction in any medium, provided the original author(s) and source are credited.

\section{References}

1. Calin A (1985) Comment on article by van der Linden et al. Evaluation of diagnostic criteria for ankylosing spondylitis: a proposal for modification of the New York criteria. Arthritis Rheum 28:357-359

2. Jimenez-Balderas FJ, Mintz G (1993) Ankylosing spondylitis: clinical course in women and men. J Rheumatol 20:2069-2072

3. Vander Cruyssen B, Ribbens C, Boonen A, Mielants H, de Vlam $\mathrm{K}$ et al (2007) The epidemiology of ankylosing spondylitis and the commencement of anti-TNF therapy in daily rheumatology practice. Ann Rheum Dis 66:1072-1077

4. Dougados M, van der Linden S, Juhlin R, Huitfeldt B, Amor B et al (1991) The European Spondylarthropathy Study Group preliminary criteria for the classification of spondylarthropathy. Arthritis Rheum 34:1218-1227

5. Collantes E, Veroz R, Escudero A, Munoz E, Munoz MC et al (2000) Can some cases of 'possible' spondyloarthropathy be classified as 'definite' or 'undifferentiated' spondyloarthropathy? Value of criteria for spondyloarthropathies. Spanish Spondyloarthropathy Study Group. Joint Bone Spine 67:516-520

6. Gomariz EM, del M, Guijo VP, Contreras AE, Villanueva M et al (2002) The potential of ESSG spondyloarthropathy classification criteria as a diagnostic aid in rheumatological practice. J Rheumatol 29:326-330

7. Rudwaleit M, van der Heijde D, Khan MA, Braun J, Sieper J (2004) How to diagnose axial spondyloarthritis early. Ann Rheum Dis 63:535-543

8. Rudwaleit M, Listing J, Brandt J, Braun J, Sieper J (2004) Prediction of a major clinical response (BASDAI 50) to tumour necrosis factor alpha blockers in ankylosing spondylitis. Ann Rheum Dis 63:665-670

9. Brandt J, Haibel H, Reddig J, Sieper J, Braun J (2002) Successful short term treatment of severe undifferentiated spondyloarthropathy with the anti-tumor necrosis factor-alpha monoclonal antibody infliximab. J Rheumatol 29:118-122

10. Rudwaleit M, van der Heijde D, Landewe R, Listing J, Akkoc N et al (2009) The development of Assessment of SpondyloArthritis international Society classification criteria for axial spondyloarthritis (part II): validation and final selection. Ann Rheum Dis 68:777-783

11. Rudwaleit M, Metter A, Listing J, Sieper J, Braun J (2006) Inflammatory back pain in ankylosing spondylitis: a reassessment of the clinical history for application as classification and diagnostic criteria. Arthritis Rheum 54:569-578

12. Wei JC, Wong RH, Huang JH, Yu CT, Chou CT et al (2007) Evaluation of internal consistency and re-test reliability of Bath ankylosing spondylitis indices in a large cohort of adult and juvenile spondylitis patients in Taiwan. Clin Rheumatol 26:1685-1691

13. Calin A, Nakache JP, Gueguen A, Zeidler H, Mielants $\mathrm{H}$ et al (1999) Defining disease activity in ankylosing spondylitis: is a combination of variables (Bath Ankylosing Spondylitis Disease Activity Index) an appropriate instrument? Rheumatol Oxf 38:878-882

14. Garrett S, Jenkinson T, Kennedy LG, Whitelock H, Gaisford P et al (1994) A new approach to defining disease status in ankylosing spondylitis: the Bath Ankylosing Spondylitis Disease Activity Index. J Rheumatol 21:2286-2291

15. Calin A, Garrett S, Whitelock H, Kennedy LG, O'Hea J et al (1994) A new approach to defining functional ability in ankylosing spondylitis: the development of the Bath Ankylosing Spondylitis Functional Index. J Rheumatol 21:2281-2285

16. Wakefield D, Montanaro A, McCluskey P (1991) Acute anterior uveitis and HLA-B27. Surv Ophthalmol 36:223-232

17. Rosenow E, Strimlan CV, Muhm JR, Ferguson RH (1977) Pleuropulmonary manifestations of ankylosing spondylitis. Mayo Clin Proc 52:641-649

18. Thai D, Ratani RS, Salama S, Steiner RM (2000) Upper lobe fibrocavitary disease in a patient with back pain and stiffness. Chest 118:1814-1816

19. Lee-Chiong TL Jr (1998) Pulmonary manifestations of ankylosing spondylitis and relapsing polychondritis. Clin Chest Med 19:747757 , ix

20. Graham DC, Smythe HA (1958) The carditis and aortitis of ankylosing spondylitis. Bull Rheum Dis 9:171-174

21. Roldan CA, Chavez J, Wiest PW, Qualls CR, Crawford MH (1998) Aortic root disease and valve disease associated with ankylosing spondylitis. J Am Coll Cardiol 32:1397-1404

22. Gerster JC (1980) Plantar fasciitis and Achilles tendinitis among 150 cases of seronegative spondarthritis. Rheumatol Rehabil 19:218-222

23. Baddoura R, Awada H, Okais J, Habis T, Attoui S et al (1997) Validation of the European Spondylarthropathy Study Group and B Amor criteria for spondylarthropathies in Lebanon. Rev Rhum Engl Ed 64:459-464

24. Boyer GS, Templin DW, Goring WP (1993) Evaluation of the European Spondylarthropathy Study Group preliminary classification criteria in Alaskan Eskimo populations. Arthritis Rheum 36:534-538 
25. Cury SE, Vilar MJ, Ciconelli RM, Ferraz MB, Atra E (1997) Evaluation of the European Spondylarthropathy Study Group (ESSG) preliminary classification criteria in Brazilian patients. Clin Exp Rheumatol 15:79-82

26. Erturk M, Alaca R, Tosun E, Duruoz MT (1997) Evaluation of the Amor and ESSG classification criteria for spondylarthropathies in a Turkish population. Rev Rhum Engl Ed 64:293300

27. Underwood MR, Dawes P (1995) Inflammatory back pain in primary care. Br J Rheumatol 34:1074-1077

28. Bollow M, Enzweiler C, Taupitz M, Golder W, Hamm B et al (2002) Use of contrast enhanced magnetic resonance imaging to detect spinal inflammation in patients with spondyloarthritides. Clin Exp Rheumatol 20:S167-S174

29. Rudwaleit M, Schwarzlose S, Hilgert ES, Listing J, Braun J et al (2008) MRI in predicting a major clinical response to anti-tumour necrosis factor treatment in ankylosing spondylitis. Ann Rheum Dis 67:1276-1281

30. Sieper J, Rudwaleit M (2005) Early referral recommendations for ankylosing spondylitis (including pre-radiographic and radiographic forms) in primary care. Ann Rheum Dis 64:659663

31. Spoorenberg A, van der Heijde D, de Klerk E, Dougados M, de Vlam K et al (1999) Relative value of erythrocyte sedimentation rate and C-reactive protein in assessment of disease activity in ankylosing spondylitis. J Rheumatol 26:980-984

32. Braun J, Pham T, Sieper J, Davis J, van der Linden S et al (2003) International ASAS consensus statement for the use of antitumour necrosis factor agents in patients with ankylosing spondylitis. Ann Rheum Dis 62:817-824

33. Braun J, Davis J, Dougados M, Sieper J, van der Linden S et al (2006) First update of the international ASAS consensus statement for the use of anti-TNF agents in patients with ankylosing spondylitis. Ann Rheum Dis 65:316-320

34. Machado P, Landewe R, Braun J, Hermann KG, Baker D et al (2010) Both structural damage and inflammation of the spine contribute to impairment of spinal mobility in patients with ankylosing spondylitis. Ann Rheum Dis 69:1465-1470
35. Kumar A, Bansal M, Srivastava DN, Pandhi A, Menon A et al (2001) Long-term outcome of undifferentiated spondylarthropathy. Rheumatol Int 20:221-224

36. Mau W, Zeidler H, Mau R, Majewski A, Freyschmidt J et al (1988) Clinical features and prognosis of patients with possible ankylosing spondylitis. Results of a 10-year followup. J Rheumatol 15:1109-1114

37. Baraliakos X, Davis J, Tsuji W, Braun J (2005) Magnetic resonance imaging examinations of the spine in patients with ankylosing spondylitis before and after therapy with the tumor necrosis factor alpha receptor fusion protein etanercept. Arthritis Rheum 52:1216-1223

38. Baraliakos X, Listing J, Rudwaleit M, Brandt J, Sieper J et al (2005) Radiographic progression in patients with ankylosing spondylitis after 2 years of treatment with the tumour necrosis factor alpha antibody infliximab. Ann Rheum Dis 64:1462-1466

39. Baraliakos X, Listing J, Brandt J, Haibel H, Rudwaleit $M$ et al (2007) Radiographic progression in patients with ankylosing spondylitis after 4 yrs of treatment with the anti-TNF-alpha antibody infliximab. Rheumatol Oxf 46:1450-1453

40. Collantes-Estevez E, Munoz-Villanueva MC, Canete-Crespillo JD, Sanmarti-Sala R, Gratacos-Masmitja J et al (2003) Infliximab in refractory spondyloarthropathies: a multicentre 38 week open study. Ann Rheum Dis 62:1239-1240

41. Brandt J, Haibel H, Cornely D, Golder W, Gonzalez J et al (2000) Successful treatment of active ankylosing spondylitis with the anti-tumor necrosis factor alpha monoclonal antibody infliximab. Arthritis Rheum 43:1346-1352

42. Braun J, Brandt J, Listing J, Zink A, Alten R et al (2002) Treatment of active ankylosing spondylitis with infliximab: a randomised controlled multicentre trial. Lancet 359:1187-1193

43. Brandt J, Khariouzov A, Listing J, Haibel H, Sorensen $\mathrm{H}$ et al (2003) Six-month results of a double-blind, placebo-controlled trial of etanercept treatment in patients with active ankylosing spondylitis. Arthritis Rheum 48:1667-1675

44. Davis JC Jr, Van der Heijde DM, Dougados M, Braun J, Cush JJ et al (2005) Baseline factors that influence ASAS 20 response in patients with ankylosing spondylitis treated with etanercept. J Rheumatol 32:1751-1754 